\title{
Adolescents with Sleep Disturbance: Causes and Diagnosis
}

\author{
Akemi Tomoda and Mika Yamazaki \\ Child Development Research Center, \\ Graduate School of Medical Sciences, \\ University of Fukui \\ Japan
}

\section{Introduction}

In our previous study, circadian rhythm sleep disorders have been reported in pediatric and adolescent populations (Tomoda, Miike, Uezono, \& Kawasaki, 1994). Pediatric practitioners now commonly encounter sleep disturbance in previously healthy children and adolescents (Boergers, Hart, Owens, Streisand, \& Spirito, 2007; Giannotti, Cortesi, Sebastiani, \& Ottaviano, 2002; Stein, Mendelsohn, Obermeyer, Amromin, \& Benca, 2001). The characteristic clinical features are well known, but the specific causes remain unknown. New types of circadian rhythm sleep disorders, such as familial advanced sleep phase syndrome (ASPS) and delayed sleep phase syndrome (DSPS), non-24-h sleep-wake syndrome (non-24), and morningnesseveningness have been described during the last decade. Such disorders are probably caused by various disturbances of circadian expression of the clock gene (Archer et al., 2003; Ebisawa et al., 2001; Iwase et al., 2002; Pirovano et al., 2005; Takimoto et al., 2005; Toh et al., 2001; Wijnen, Boothroyd, Young, \& Claridge-Chang, 2002). Polymorphisms in clock genes are known to induce circadian rhythm sleep disorders. For example, mutations in the period2 (Per2) gene (S662G) or casein kinase1 d (CK16) gene (T44A) cause familial ASPS; furthermore, missense polymorphisms in the Per3 (V647G) and CK1e (S408N) genes increase or decrease the risk of developing DSPS.

In our clinical practices, we recognized that the majority of our patients have a circadian rhythm disorder even though they usually do not mention or recognize this problem at the first interview. We hypothesized that there could be certain relationship between biological rhythm disorders in these patients and their indefinite symptoms as well as their sleep disturbances. This chapter introduces sleep patterns, circadian rhythms of core body temperature (CBT), glucose metabolism, and human clock gene profile in children and adolescents with sleep disturbance.

\section{Methods}

\subsection{Protocol}

This study included 22 unmedicated patients with sleep disturbances (Table 1). All patients satisfied diagnostic criteria for circadian rhythm sleep disorders of the Diagnostic and Statistical Manual of Mental Disorders, 4th Edition, Text Revision (DSM-IV-TR®). The 
diagnosis was made by three raters using the Structured Clinical Interview. The severity of those symptoms was measured using self-reported ratings (performance status scores), as described previously \{Kuratsune, 2002 \#890;Tomoda, 2007 \#925\}. Their performance status scores on admission were higher than 5 (mean, 5.6; SD, 0.8).

For at least one month prior to the initial assessment, prophylactic drugs (e.g. tranquilizers) were not given. Patients who had just recently started treatment with antidepressants or hypotension drugs, or who were diagnosed as having neurological illness, migraine, obstructive sleep apnea, below average intelligence, or serious psychopathology were excluded from the study. Serious psychopathology was evaluated by referral to at least one psychiatrist if the patient presented with some indicative symptoms. No patient had a history of drug abuse. Table 1 presents physical characteristics of the present subjects. The protocol was approved by the Committee of Life Ethics, Graduate School of Medicine, Kumamoto University. All participants gave written informed consent.

\begin{tabular}{lccc}
\hline & $\begin{array}{c}\text { Patient } \\
(\mathrm{n}=22)\end{array}$ & $\begin{array}{c}\text { Control } \\
(\mathrm{n}=9)\end{array}$ & $\mathrm{p}$-value \\
\hline Mesor $\left({ }^{\circ} \mathrm{C}\right)$ & $36.71 \pm 0.17$ & $36.61 \pm 0.18$ & $\mathrm{p}>0.1$ \\
Double amplitude $\left({ }^{\circ} \mathrm{C}\right)$ & $0.85 \pm 0.36$ & $1.51 \pm 0.37$ & $\mathrm{p}<0.005$
\end{tabular}

Acrophase (clock time):

In advanced patients $(\mathrm{n}=6) \quad 15.10 \pm 1.02 \quad 17.44 \pm 1.34 \quad \mathrm{p}<0.005$

In delayed patients $(\mathrm{n}=16) \quad 20.02 \pm 1.18 \quad 17.44 \pm 1.34 \quad \mathrm{p}<0.005$

p-value: significant difference in ANOVA.

Table 1. Circadian rhythm of core body temperature: Results of a cosinor analysis.

\subsection{Recording of the sleep-wake rhythm}

Each subject kept daily recordings (logs) of their time of sleeping and awaking for 4 or longer weeks. These logs were used to analyze their sleep pattern during a 24-hour period. According to the International Classification of Sleep Disorders (ICSD) revised by the Association of Sleep Disorders Center in North America in 1990 (Diagnostic Classification Committee, 1990), our patients were diagnosed as either delayed sleep phase syndrome (DSPS), non-24-hour sleep-wake syndrome (non-24), irregular sleep, or long sleeper. DSPS is characterized by difficulty in falling asleep at night and an inability to be easily aroused in the morning, and this diagnosis corresponds to DSM-III-R: Sleep-Wake Schedule Disorder. Non-24 presents sleep-wake cycles longer than 24 hours, and this corresponds also to DSMIII-R: 307.45. Irregular sleep is characterized with no recognizable circadian patterns of sleep onset or waking time, and this does not correspond a sleep disorder diagnosis in DSM-III-R. Long sleeper have sleep times longer than 9 hours although they do not have any organic abnormalities, and this correspond to DSM-III-R: 780.54. 


\subsection{Circadian rhythm of core body temperature}

Continuous monitoring of CBT for 3 days and at every one minute was carried out by using a deep body temperature monitor (Terumo Corp., Tokyo, Japan).

Mean values of the 3 measurements at each time point during the 3 consecutive days were used in the examination. A chronograph was used to determine the circadian rhythm, and the single cosinor method, to analyze the CBT circadian variation for both groups (Halberg et al. 1977). A cosine curve with a period of 24 hours was fitted to the data by using the least squares method, and the following parameters were obtained: mesor $\left({ }^{\circ} \mathrm{C}\right.$, rhythm-adjusted average), amplitude (difference between the highest and lowest temperature), and acrophase (time of the highest point in the rhythm defined by a fitted cosine curve). To obtain data in normal age-matched persons, we recruited 9 healthy school children as volunteers. They were 6 males and 3 females, aged 10-21 years (mean age, 17.3 years), and who had no mental retardation, physical problems, or psychiatric psychopathology.

In statistical analysis, ANOVA was used, and when the $p$-value was less than 0.05 , the group difference was considered to be statistically significant.

\subsection{Hormonal secretion profiles}

Melatonin, cortisol, $\beta$-endorphin and temperature circadian rhythms. 24-hour blood sampling was performed through an indwelling catheter in a forearm vein at 4-hour intervals. Each blood sample was immediately centrifuged at $4^{\circ} \mathrm{C}$ and stored at $-80^{\circ} \mathrm{C}$ until melatonin, cortisol and ß-endorphin were assayed by radioimmuno assay (RIA). The lower limit of melatonin sensitivity was determined to be $3 \mathrm{pg} / \mathrm{ml}$.

Comparative data concerning the timing of hormonal production were obtained for a group of six normally-sighted healthy male volunteers aged 20-22 years (mean age, 20.6 years) who had no mental retardation or serious psychopathology.

The recordings of the deep body temperature were carried out with a deep body temperature monitor (Terumo Co., Tokyo, Japan) below Lanz's point every 1 minute for three consecutive days for the patient and the control group.

Both a chronograph and the single cosinor method were used to examine the rhythmicity and to analyze the circadian variation.

A cosine curve with a period of 24 hours was fitted to the data using the least squares method, and the following parameters were established; mesor (rhythm-adjusted mean), amplitude (difference between mesor and nadir) and acrophase (lag of the crest time in the best fitted cosine curve in relation to a given reference time). When the p-value was less than 0.05 , the rhythm was considered to be statistically significant.

\subsection{Evaluation of carbohydrate metabolism}

A 3-h oral glucose tolerance test was performed the morning after a subject had fasted overnight. After the fasting blood sample was drawn, a subject was given a solution containing a predetermined amount of glucose based on body weight $(1.75 \mathrm{~g} / \mathrm{kg}$ to a maximum of $75 \mathrm{~g}$ ). After glucose ingestion, blood samples were drawn at 30, 60, 90, 120, 150, and $180 \mathrm{~min}$ to measure blood glucose (BG) levels and immunoreactive insulin (IRI) response. Serum BG level was determined using the glucose oxidase reaction method. Serum IRI response was measured using radioimmunoassay (Eiken Chemical Co. Ltd., Tokyo, Japan). The BG levels, IRI response, cumulative BG (sigma BG), cumulative IRI (sigma IRI), insulin/glucose ratio (delta IRI/delta BG), and insulinogenic index (sigma IRI/sigma BG) 
were then compared to normal control data that had been reported previously for 8 subjects aged 12-16 years without a personal or family history of diabetes mellitus or any factor affecting glucose metabolism (Iwatani et al., 1997). The control subjects were within $\pm 2.0 \mathrm{SD}$ of standard height, and within $\pm 20 \%$ of ideal body weight. All indices were calculated using the same methods as those reported previously (Iwatani et al., 1997).

\subsection{Experimental procedure for human clock gene measurement}

Subjects were exposed to natural and fluorescent lighting of the institution during the awake period. Lights were turned off during the sleeping period. An indwelling catheter was placed in the antecubital vein for a 24 -h period. Blood samples were taken at $4-\mathrm{h}$ intervals beginning at 10:00 a.m. on the second day of hospitalization and continued until 6:00 a.m. of the following day. Samples were obtained under dim light (less than 30 Lux) without waking the patients during the sleeping period. We previously reported that subjects 12 years of age and older show similar metabolic characteristics to those of an adult (Iwatani et al., 1997). Therefore, we recruited 10 men aged 20-41 years (mean age, 27.4 years; SD, 6.1 years) as normal subjects from whom data were obtained (Reppert \& Weaver, 2002; Takimoto et al., 2005): none had below-average intelligence, physical problems, psychiatric psychopathology, or irregular sleep or meal schedules.

Blood was collected in blood RNA kit tubes (PAXgene; Qiagen K.K., Tokyo, Japan). The tubes were incubated at room temperature for $24 \mathrm{~h}$; then the total ribonucleic acid (RNA) was isolated according to the manufacturer's instructions. For quality assessment of total RNA during protocol development, deoxyribonucleic acid (DNA) digestion of the samples was performed with the RNase-Free DNase Set (Qiagen K.K.). Synthesis of complementary DNA was conducted (ReverTra Ace- $\alpha-\circledR$; Toyobo Co. Ltd., Osaka, Japan) for use with the reversetranscription polymerase chain reaction (RT-PCR) kit. Quantitative real-time RT-PCR (TaqMan ${ }^{\circledR}$ ) was performed using a sequence detection system (ABI PRISM® 7900; Applied Biosystems, Foster City, CA) to determine the expression levels of $h$ Per1, hPer2, hPer3, hBmal1, $h$ Clock, and housekeeping gene $h \beta$-actin expression relative to $h \beta$-actin, with the standard protocol described by the manufacturer. Relative expression of the clock gene was determined as the ratio of expression of the clock gene to that of the $\beta$-actin gene for each sample. Values were normalized so that the peak value equaled $100 \%$. The TaqMan® $h \beta$-actin control reagents and primer sets, Assays-on-Demand ${ }^{\mathrm{TM}}$ Gene Expression Product for hPer1, hPer2, hPer3, hBmal1, and hClock were purchased from Applied Biosystems for the following: hPer1, Hs00242988_m1; hPer2, Hs00256144_m1; hPer3, Hs00213466_m1; hBmal1, Hs00154147_m1; hClock, Hs00231857_m1. In addition, hPer2 was selected as the daily expression of the clock gene for determination of the circadian profile (Takimoto et al., 2005).

\section{Results}

\subsection{Sleep-awake rhythm disturbance}

Based on the self-recorded sleep-wake logs, all patients were diagnosed as having one of the 4 sleep disturbances, i.e., DSPS, non-24, irregular, and long sleeper. Among patients in these 4 disease categories, there were no significant differences in the duration of sleep disturbance, ages when the symptom first started, and their current age.

More than $80 \%$ of our patients with sleep disorders showed a tendency of a day/night reversal life style, especially in the period right after termination of school social life. An overnight EEG study revealed a decrease in deep NREM sleep and delayed latency of the 
REM sleep phase (unpublished data). Most of them need about 10 hours sleep to keep awake for the rest of the daytime. These data suggest a deteriorated quality of night sleep. Even though sleep disorders are considered to begin in childhood and adolescents, there have been no in depth reports on this problem.

\subsection{Abnormal core body temperature rhythm}

It has been known that the sleep-awake circadian rhythm and other circadian rhythms such as the CBT and hormonal secretion rhythms are closely related to each other. With this background we examined the circadian CBT rhythm in our cases using a special instrument for CBT measurement. The CBT rhythm has been considered to well-match the brain temperature rhythm, according to a basic study. The 41 subjects studied ( 24 males and 17 females), aged between 10 to 19 years (mean: 15.2 years), were referred to our clinic. To obtain data for normal age-matched controls, we recruited healthy school children as volunteers. The comprised 6 males and 3 females, aged 10-21 years (mean: 17.3 years) for CBT controls. The results are summarized in Table 1. In those patients, the mesor of the circadian CBT rhythm was significantly higher than that in the normal controls. In particular, it is noteworthy that the mean CBT at nighttime was obviously higher in the patients than in normal controls. In those patients, the nadir was also significantly higher than in the normal subjects. The nadir recorded on appearance was significantly delayed in the patients compared to in the normal subjects.

In those patients, the amplitude of circadian CBT rhythm was significantly lower $(0.85 \pm$ $\left.0.36^{\circ} \mathrm{C}\right)$ than the normal subjects $\left(1.51 \pm 0.37^{\circ} \mathrm{C}\right)(P<0.005)$. Acrophase in the control subjects was recorded on $17.44 \pm 1.34 \mathrm{PM}$, whereas it was advanced in 6 patients to $15.10 \pm 1.02 \mathrm{PM}$ $(P<0.005)$, and delayed in 16 patients to $20.02 \pm 1.18 \mathrm{PM}(P<0.005)$. Advance or delay was determined in comparison to the time defined in the control subjects. In our subjects, there were no rhythmical changes in their CBT.

\subsection{Disturbed hormonal secretion profiles}

We have studied the hormonal circadian secretion rhythm, such as for melatonin, cortisol and $\beta$-endorphin. Each of them showed abnormal behavior, that is, a delayed peak secretion time and a decrease in the secreted amount. As to cortisol secretion in the patients, the area under the curve (AUC) was significantly smaller than in normal controls. In addition, the cortisol peak secretion time was significantly delayed.

These data suggested that circadian rhythms are deranged in our patients, and clearly explain that the starting time of daily life is seriously delayed, because of delayed preparation for mental and physical activity supporting daily life. We would like to emphasize the reason why those patients showed a bad condition in the morning and a relatively good condition in the afternoon. The decreased total level of hormonal secretion may be the main cause of the inactivity, dullness and stagnant condition.

\subsection{Disturbed carbohydrate metabolism}

Glucose tolerance was significantly lower in the patients than in normal controls: the mean sigma blood glucose level was significantly higher $(P<0.05)$ and the insulinogenic index was significantly lower $(P<0.05)$ in the patient group than in controls (Miike, Tomoda, Jhodoi, Iwatani, \& Mabe, 2004).

The mean blood glucose (BG) level was not significantly higher in the patient group than in the controls at any time interval following oral glucose ingestion, except at 30 and 120 min 
(both $P<0.05$ ) (Tomoda, Kawatani, Joudoi, Hamada, \& Miike, 2009). The mean plasma insulin concentration in the patient group was not significantly different from the controls at any time interval following oral glucose ingestion, except at 120 and $150 \mathrm{~min}(P<0.001$ and $P<0.05$, respectively). However, individual patient insulin levels varied widely compared with the corresponding BG levels. The insulin level did not correlate with the BG level in some patients. The mean sigma BG level in the patient group was significantly higher than that of controls $(910.3 \pm 189.9$ vs. $865.1 \pm 60.5 \mathrm{mg} / \mathrm{dl}, P=0.027)$. However, the mean sigma IRI was not significantly different (patients vs. controls $=431.6 \pm 194.8$ vs. $892.8 \pm 440.5 \mu \mathrm{U} / \mathrm{ml}, P=0.103$ ). The insulin/glucose ratio, the initial insulin response $30 \mathrm{~min}$ after glucose ingestion, was not significantly different (patients vs. controls $=0.95 \pm 0.63$ vs. $2.43 \pm 1.03, P=0.315$ ). However, a significant difference was found in the insulinogenic index (patients vs. controls $=0.48 \pm 0.20$ vs. $1.04 \pm 0.50, P=0.044)$. The results are summarized in Table 2 .

\subsection{Abnormal mammalian circadian clock}

18 of 22 unmedicated patients were examined. The mRNA level of hPer2 was significantly higher at 6:00 in the control subjects. In contrast, the mRNA level of $h P e r 2$ was higher at 6:00 in only 3 patients, at 2:00 in 3, at 10:00 in 4, at 14:00 in 3, and at 18:00 in 5. The timing of the $h$ Per 2 peak expression level was significantly later in the patients than in the control subjects $(P<0.05$, Mann-Whitney's $U$-test). The most phase-advanced cases (cases $1,2,11)$ showed the hPer2 peak at 2:00, although the most phase-delayed cases (cases 9, 10, 15-17) showed the $h$ Per2 peak at 18:00.

There were no significant differences in expression levels of $h$ Per1, hPer3, hBmal1, hClock.

\section{Discussion}

Deranged circadian rhythms have been well recognized in jet lag. In this condition, one may have symptoms, and i.e. dysfunction of the autonomic nervous system, sleep awake rhythm, mental and physical activity. We presume that those patients with sleep disturbance suffered from an atypical but continuous jet lag condition in their daily life.

The international classification of sleep disorders (ICSD) was revised as a new sleep disorder nosology by the Association of Sleep Disorders Center in North America in 1990. Circadian rhythm sleep disorders, such as the delayed sleep phase syndrome (DSPS) and the non-24-hour sleep-wake syndrome, have been described as new types of sleep-wake disorders in the last decade. In this study, we presented children or adolescents who were evaluated as not having physical abnormalities, psychiatric disorders, or specific social problems, but they were suspected to have sleep disturbance because of their daily life pattern. They were healthy in terms of physical and psychiatric examinations, but unable to attend school because their overall conditions did not allow. Those patients who satisfied our inclusion criteria to this study accounted for $40 \%$ of the total school refusal cases whom we examined in a 2-year period. This portion is quite large, and indicates the difficulty to prescribe appropriate therapy for these patients.

In our study, all 22 patients were diagnosed as having sleep-wake rhythm disturbance based on their sleep log evaluation and CBT monitoring. Their body temperature rhythm was disturbed in the manner typically shown in adult sleep disorder patients. Among our 6 school refusal patients diagnosed as having non-24, 3 did not show clear rhythm of CBT. Because non-24 is considered most difficult to treat among the 4 categories of sleep disorder, this therapeutic difficulty could be attributable to the severely disturbed CBT rhythm. 


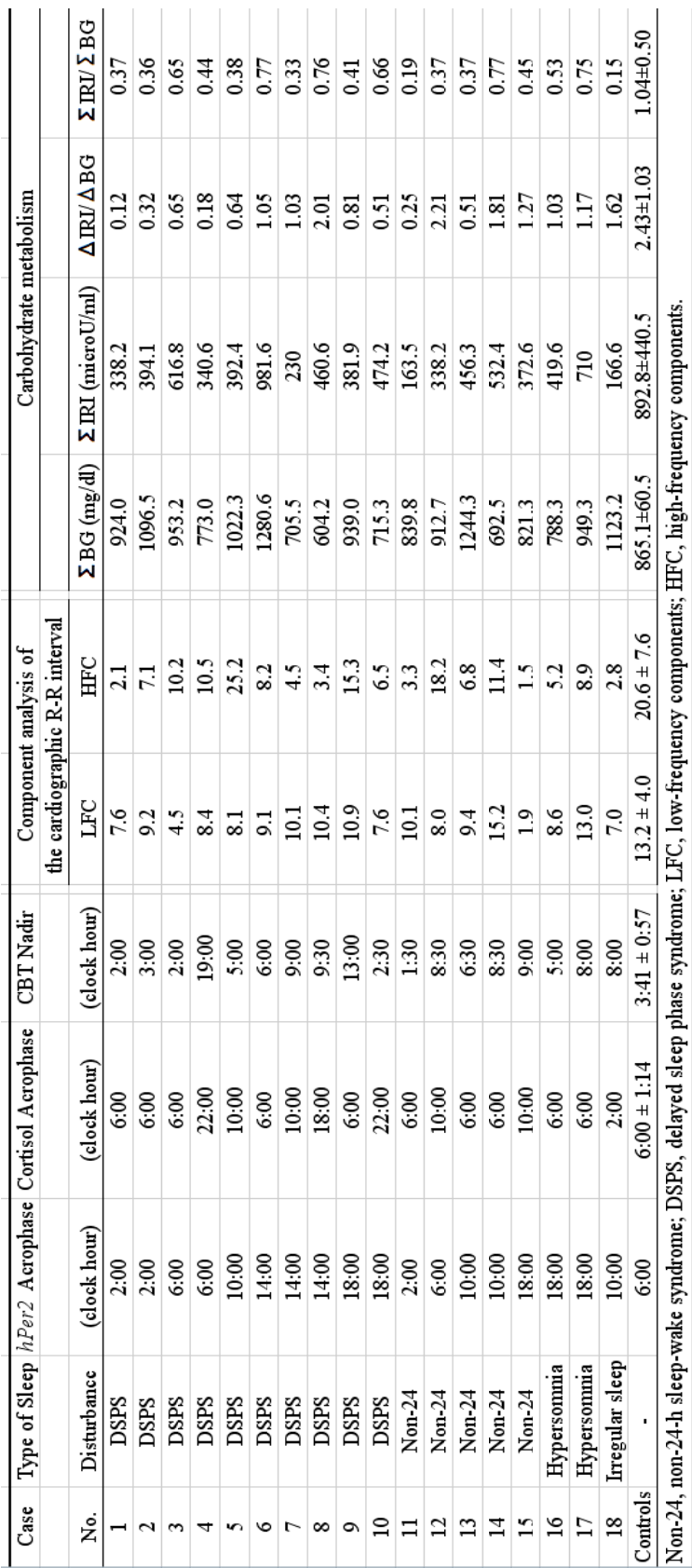

Table 2. Type of sleep disturbance, and times of hPer2 peak, cortisol peak, and lowest core body temperature (CBT) over $24 \mathrm{~h}$, and results of component analysis of the cardiographic R-R interval and glucose tolerance test of each patient(Tomoda et al., 2009). 
The 2 biological rhythms (sleep and CBT) are sometimes desynchronized with each other, e.g., when the person was completely isolated from time cues. Once the desynchronization occurred, psychosomatic symptoms, such as headache, gastrointestinal discomfort, or general fatigue. These symptoms could make the affected person unable to perform ordinary daily activities.

Furthermore, our findings obtained in this study suggest that physiological homeostasis might be seriously impaired by sleep deprivation and emotional distress, as reflected clearly by depressive symptoms in these patients. Easy fatigability and disturbed learning and memorization are among the primary characteristics of sleep disturbance and chronic fatigue in adolescents (Miike et al., 2004). Fatigue and gastrointestinal discomfort were quite severe in our patients. Another feature of this illness is the individuality of symptom patterns and the unpredictability of symptom severity.

It is particularly interesting that diurnal hypersecretion of glucocorticoids and altered regulation of the hypothalamo-pituitary-adrenocortical axis are known in patients with poorly controlled or uncontrolled diabetes (Archer et al., 2003; Chiodini et al., 2006; Roy, Roy, \& Brown, 1998). We found no cortisol hypersecretion in the present patients, suggesting the absence of diabetic status. However, those patients with sleep disturbance had glucoregulatory dysfunction. Results of a previous study show that emotionally stressful events result in hyperglycemia in diabetic patients (Lustman, Carney, \& Amado, 1981). On the other hand, sleep deficit has a harmful impact on carbohydrate metabolism and endocrine function, even in healthy subjects (Spiegel, Leproult, \& Van Cauter, 1999). Abnormalities of the biological stress response (hypothalamic-pituitary-adrenal axis and autonomic nervous system) were also identified in a previous animal study, the results of which suggested that cortisol can act directly on the central nervous system (Sandoval, Ping, Neill, Morrey, \& Davis, 2003). Multiple factors including autonomic nervous system dysfunction, derangement of neuropeptides in the hypothalamus, and hormonal imbalance might also affect the glucoregulatory metabolism.

The biological clock (circadian clock) in human beings is formed and regulated through interrelationships of various clock genes such as Per1, Per2, Per3, Bmal1, Clock, Cry1, Cry2, Bmal, Rev-ervA, CK1 d/e, and glycogen synthase kinase 3-b (GSK3ß) (Ebisawa et al., 2001; Gietzen \& Virshup, 1999; Jones et al., 1999; Takano et al., 2004; Toh et al., 2001; Vanselow et al., 2006). Currently, the markers of circadian rhythms are considered to be the profiles of plasma melatonin, cortisol, and core body temperature (Tomoda, Miike, Yonamine, Adachi, \& Shiraishi, 1997). However, even if these markers show normal rhythmic patterns, certain patients suffer from circadian rhythm sleep disorders and indeterminate symptoms, suggesting that these markers may not be reliable for the diagnosis of circadian rhythm sleep disorders.

Presumably, autonomic and metabolic dysfunction causing sleep disturbance may be related to the hPer 2 phase shift because of chronobiological abnormality. Results of a previous study indicate that such disturbances might be related closely to the desynchronization of biorhythms, particularly the circadian rhythm of body temperature and the sleep-wake rhythm (Tomoda, Jhodoi, \& Miike, 2001; Tomoda et al., 2000). Previous and present results suggest that sleep deprivation may originate from a dysfunctional network of brain areas related to the circadian rhythm and peripheral nervous system involved in the autonomic nervous system including cardiac function and gastrointestinal digestion. However, dysregulation of the circadian rhythm is neither the only nor the 
dominant factor in the pathogenesis of such conditions. Immunological, autonomic, and neuroendocrine abnormalities might be mutually dependent and reinforcing factors. More studies must be done to elucidate this mechanism and to reveal the relation between clock gene expression in the suprachiasmatic nucleus and the peripheral blood cells. Furthermore, additional study of a larger series of cases will elucidate the usefulness of this technique.

\section{References}

[1] Tomoda A, Kawatani J, Joudoi T, Hamada A, Miike T. Metabolic dysfunction and circadian rhythm abnormalities in adolescents with sleep disturbance. Neuroimage 2009;47 Suppl 2:T21-6.

[2] Tomoda A, Miike T, Uezono K, Kawasaki T. A school refusal case with biological rhythm disturbance and melatonin therapy. Brain Dev 1994;16(1):71-6.

[3] Boergers J, Hart C, Owens JA, Streisand R, Spirito A. Child sleep disorders: associations with parental sleep duration and daytime sleepiness. J Fam Psychol 2007;21(1):88-94.

[4] Giannotti F, Cortesi F, Sebastiani T, Ottaviano S. Circadian preference, sleep and daytime behaviour in adolescence. J Sleep Res 2002;11(3):191-9.

[5] Stein MA, Mendelsohn J, Obermeyer WH, Amromin J, Benca R. Sleep and behavior problems in school-aged children. Pediatrics 2001;107(4):E60.

[6] Archer SN, Robilliard DL, Skene DJ, Smits M, Williams A, Arendt J, et al. A length polymorphism in the circadian clock gene Per3 is linked to delayed sleep phase syndrome and extreme diurnal preference. Sleep 2003;26(4):413-5.

[7] Ebisawa T, Uchiyama M, Kajimura N, Mishima K, Kamei Y, Katoh M, et al. Association of structural polymorphisms in the human period3 gene with delayed sleep phase syndrome. EMBO Rep 2001;2(4):342-6.

[8] Iwase T, Kajimura N, Uchiyama M, Ebisawa T, Yoshimura K, Kamei Y, et al. Mutation screening of the human Clock gene in circadian rhythm sleep disorders. Psychiatry Res 2002;109(2):121-8.

[9] Pirovano A, Lorenzi C, Serretti A, Ploia C, Landoni S, Catalano M, et al. Two new rare variants in the circadian "clock" gene may influence sleep pattern. Genet Med 2005;7(6):455-7.

[10] Takimoto M, Hamada A, Tomoda A, Ohdo S, Ohmura T, Sakato H, et al. Daily expression of clock genes in whole blood cells in healthy subjects and a patient with circadian rhythm sleep disorder. Am J Physiol Regul Integr Comp Physiol 2005;289(5):R1273-9.

[11] Toh KL, Jones CR, He Y, Eide EJ, Hinz WA, Virshup DM, et al. An hPer2 phosphorylation site mutation in familial advanced sleep phase syndrome. Science 2001;291(5506):1040-3.

[12] Wijnen H, Boothroyd C, Young MW, Claridge-Chang A. Molecular genetics of timing in intrinsic circadian rhythm sleep disorders. Ann Med 2002;34(5):386-93.

[13] Iwatani N, Miike T, Kai Y, Kodama M, Mabe H, Tomoda A, et al. Glucoregulatory disorders in school refusal students. Clin Endocrinol (Oxf) 1997;47(3):273-8.

[14] Reppert SM, Weaver DR. Coordination of circadian timing in mammals. Nature 2002;418(6901):935-41.

[15] Miike T, Tomoda A, Jhodoi T, Iwatani N, Mabe H. Learning and memorization impairment in childhood chronic fatigue syndrome manifesting as school phobia in Japan. Brain Dev 2004;26(7):442-7. 
[16] Roy MS, Roy A, Brown S. Increased urinary-free cortisol outputs in diabetic patients. J Diabetes Complications 1998;12(1):24-7.

[17] Chiodini I, Di Lembo S, Morelli V, Epaminonda P, Coletti F, Masserini B, et al. Hypothalamic-pituitary-adrenal activity in type 2 diabetes mellitus: role of autonomic imbalance. Metabolism 2006;55(8):1135-40.

[18] Lustman P, Carney R, Amado H. Acute stress and metabolism in diabetes. Diabetes Care 1981;4(6):658-9.

[19] Spiegel K, Leproult R, Van Cauter E. Impact of sleep debt on metabolic and endocrine function. Lancet 1999;354(9188):1435-9.

[20] Sandoval DA, Ping L, Neill AR, Morrey S, Davis SN. Cortisol acts through central mechanisms to blunt counterregulatory responses to hypoglycemia in conscious rats. Diabetes 2003;52(9):2198-204.

[21] Hastings MH. Central clocking. Trends Neurosci 1997;20(10):459-64.

[22] Gietzen KF, Virshup DM. Identification of inhibitory autophosphorylation sites in casein kinase I epsilon. J Biol Chem 1999;274(45):32063-70.

[23] Jones CR, Campbell SS, Zone SE, Cooper F, DeSano A, Murphy PJ, et al. Familial advanced sleep-phase syndrome: A short-period circadian rhythm variant in humans. Nat Med 1999;5(9):1062-5.

[24] Takano A, Uchiyama M, Kajimura N, Mishima K, Inoue Y, Kamei Y, et al. A missense variation in human casein kinase I epsilon gene that induces functional alteration and shows an inverse association with circadian rhythm sleep disorders. Neuropsychopharmacology 2004;29(10):1901-9.

[25] Vanselow K, Vanselow JT, Westermark PO, Reischl S, Maier B, Korte T, et al. Differential effects of PER2 phosphorylation: molecular basis for the human familial advanced sleep phase syndrome (FASPS). Genes Dev 2006;20(19):2660-72.

[26] Tomoda A, Miike T, Yonamine K, Adachi K, Shiraishi S. Disturbed circadian core body temperature rhythm and sleep disturbance in school refusal children and adolescents. Biol Psychiatry 1997;41(7):810-3.

[27] Tomoda A, Miike T, Yamada E, Honda H, Moroi T, Ogawa M, et al. Chronic fatigue syndrome in childhood. Brain Dev 2000;22(1):60-4.

[28] Tomoda A, Jhodoi T, Miike T. Chronic fatigue and abnormal biological rhythms in school children. J Chronic Fatigue Syndrome 2001;60:607-12. 


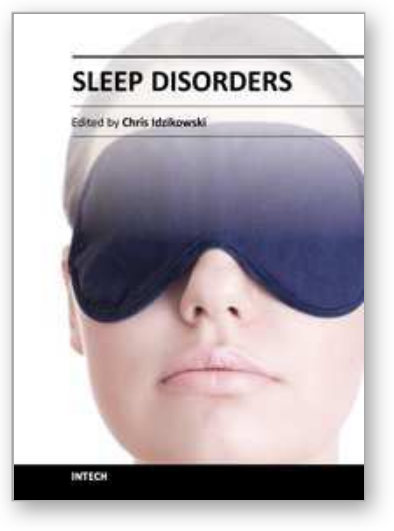

\author{
Sleep Disorders \\ Edited by Dr. Chris Idzikowski
}

ISBN 978-953-51-0293-9

Hard cover, 190 pages

Publisher InTech

Published online 14, March, 2012

Published in print edition March, 2012

For progress to be maintained in a clinical field like sleep medicine, unimpeded, unrestricted access to data and the advances in clinical practice should be available. The reason why this book is exciting is that it breaks down the barriers to dissemination of information, providing scientists, physicians, researchers and interested individuals with a valuable insight into the latest diverse developments within the study of sleep disorders. This book is a collection of chapters, which can be viewed as independent units dealing with different aspects and issues connected to sleep disorders, having in common that they reflect leading edge ideas, reflections and observations. The authors take into account the medical and social aspects of sleep-related disorders, concentrating on different focus groups, from adults to pregnant women, adolescents, children and professional workers.

\title{
How to reference
}

In order to correctly reference this scholarly work, feel free to copy and paste the following:

Akemi Tomoda and Mika Yamazaki (2012). Adolescents with Sleep Disturbance: Causes and Diagnosis, Sleep Disorders, Dr. Chris Idzikowski (Ed.), ISBN: 978-953-51-0293-9, InTech, Available from: http://www.intechopen.com/books/sleep-disorders/adolescents-with-sleep-disturbance

\section{INTECH}

open science | open minds

\section{InTech Europe}

University Campus STeP Ri Slavka Krautzeka 83/A 51000 Rijeka, Croatia Phone: +385 (51) 770447 Fax: +385 (51) 686166 www.intechopen.com

\section{InTech China}

Unit 405, Office Block, Hotel Equatorial Shanghai No.65, Yan An Road (West), Shanghai, 200040, China 中国上海市延安西路65号上海国际贵都大饭店办公楼405单元 Phone: +86-21-62489820

Fax: $+86-21-62489821$ 
(C) 2012 The Author(s). Licensee IntechOpen. This is an open access article distributed under the terms of the Creative Commons Attribution 3.0 License, which permits unrestricted use, distribution, and reproduction in any medium, provided the original work is properly cited. 